\section{Additive Manufacturing of Structural Cores and Washout Tooling for Autoclave Curing of Hybrid Composite Structures}

\author{
Daniel-Alexander Türk ${ }^{1,2}$ \\ Department of Mechanical and Process Engineering, \\ Product Development Group Zürich, \\ ETH Zurich, \\ Zurich 8092, Switzerland \\ e-mail: dturk@caltech.edu
}

\section{Andreas Ebnöther}

Department of Mechanical and Process Engineering, Product Development Group Zürich,

ETH Zurich,

Zurich 8092, Switzerland

\author{
Markus Zogg \\ Inspire AG, \\ Technoparkstrasse 1, \\ Zürich 8005, Switzerland
}

\author{
Mirko Meboldt \\ Department of Mechanical and Process Engineering, \\ Product Development Group Zürich, \\ ETH Zurich, \\ Zurich 8092, Switzerland
}

This paper presents a study combining additive manufactured (AM) elements with carbon fiber-reinforced polymers (CFRP) for the autoclave curing of complex-shaped, lightweight structures. Two approaches were developed: First, structural cores were produced with AM, over-laminated with CFRP, and co-cured in the autoclave. Second, a functional hull is produced with AM, filled with a temperature- and pressure-resistant material, and overlaminated with CFRP. After curing, the filler-material is removed to obtain a hollow lightweight structure. The approaches were applied to hat stiffeners, which were modeled, fabricated, and tested in three-point bending. Results show weight savings by up to $5 \%$ compared to a foam core reference. Moreover, the AM element contributes to the mechanical performance of the hat stiffener, which is highlighted by an increase in the specific bending stiffness and the first failure load by up to $18 \%$ and $310 \%$. Results indicate that the approaches are appropriate for composite structures with complex geometries. [DOI: 10.1115/1.4040428]

\section{Introduction}

1.1 Motivation. Efficient lightweight structures are a tradeoff between performance attained and manufacturing effort required. The attainment of minimal weight uses technical concepts such as the selection of materials, the utilization of shape, the optimization of topology, and multifunctionality [1]. However, too often, optimal lightweight designs for composite structures cannot be produced, or have to make way for simplified embodiments, as

\footnotetext{
${ }^{1}$ Corresponding author.

${ }^{2}$ Present address: Graduate Aerospace Laboratories, California Institute of Technology, 1200 East California Boulevard, Pasadena, CA 91125.

Manuscript received December 20, 2017; final manuscript received May 19 , 2018; published online July 9, 2018. Assoc. Editor: Zhijian J. Pei.
}

their manufacturability is constrained by traditional tooling restrictions.

Sandwich structures and stiffened panels are composite design concepts that exhibit excellent bending stiffness at low weight and therefore are used in manifold applications ranging from aerospace to transportation [2-4]. Embodiments of such structures use lightweight, yet strong and stiff materials in tension and compression for the facings and lightweight core materials that support transverse and shear loads. For high-performance applications, carbon fiber-reinforced polymers (CFRP) are used as facings, and foams or honeycombs are applied as core materials.

In typical sandwich structures, the load is inhomogenously distributed in the core, resulting in areas that are less loaded than others or that even require no structural material at all. They ideally would require graded mechanical properties and complex shapes, and while studies propose optimized designs for sandwiches [5-11] and stiffeners [12-15], too often they cannot be produced. Instead, stiffeners employed in state-of-the-art structures, metallic and composite, are generally regular in shape and have a constant cross-sections and material thickness [16]. The same applies for sandwich structures that typically consist of a series of planar panels with constant mechanical properties [17].

The autoclave prepreg process is a state-of-the art technique for the production of high-performance CFRP parts. In this process, PREimPREGnated fiber reinforcements are cured at elevated pressure and temperature to consolidate the layup. This process allows to achieve CFRP parts with high fiber volume content and low porosity [18]. The manufacturing of CFRP stiffeners and sandwiches involves the machining or forming of the core (e.g., foam), which is inserted between the facings during the layup and remains in the final composite part. For regular-shaped stiffeners, a removable metallic tool may be used.

The fabrication of more complex-shaped composite structures requires either washout or multipiece clamshell tooling. Washout tooling provides the layup surface for enclosed composite structures and is dissolved after curing. A widely used technique for small volume applications is based on semifinished materials (e.g., ceramics). They can be pressed into plates, which are machined to the desired and sealed before applying the CFRP layup. They also consist as powder material, which is mixed with water and poured into a mold where it cures and dries. Then, the washout tool is removed from the mold, sealed, and the layup is applied [19].

The gap between optimal and realizable composite designs results from traditional manufacturing limitations. In fact, the achievable structural complexity is limited by subtractive manufacturing technologies, resulting in either flat-shaped designs (integral design approach) or in complex structures with a high number of heavy interfaces (differential design approach). In both cases, the lightweight potential remains untapped.

Recently, additive manufacturing (AM) has increasingly been used for the production of fast, on-demand tools, and molds for the prototyping and fabrication of composite parts [20]. AM encompasses a set of production technologies allowing complex geometries to be created from digital models. The process generally works by solidifying or depositing material layer by layer only where required [21].

Additive manufactured tooling applications include layup tools, washout tools, and master models. AM layup tools are directly produced from a digital file, potentially reducing the lead and the manufacturing time for complex-shaped applications.

1.2 Past Work on Combining Additive Manufacturing With Fiber-Reinforced Polymers. Stratasys, Ltd. has become an important player in the field of AM tooling by developing a range of materials and design guidelines for in-autoclave tooling of composite parts using fused deposition modeling (FDM) [22]. $\mathrm{Li}$ et al. characterized fiber-reinforced polymers (FRP) layup tools made of ULTEM 9085, a poly-ether-imide, subjected to pressure 
and elevated temperatures amounting up to $121^{\circ} \mathrm{C}$ for vacuumassisted resin transfer molding [23]. Lušic performed a case study assessing ULTEM 1010 under autoclave processing conditions up to a pressure of 3 bar showing the material savings of up to $84 \%$ compared to a solid tool [24]. Recent approaches embed reinforcement fibers in the extrusion process for the freeform fabrication of CFRP [25]. Oak Ridge National Laboratory is working on big area additive manufacturing for in-autoclave tooling with high-temperature thermoplastic materials. Such a material is the polyphenylene sulfide with carbon fiber loadings of up to $60 \%$ by weight, resulting in tensile strengths of up to $66 \mathrm{MPa}$ [26].

Recently, FDM and Binder Jetting are two AM technologies that have been used for the fabrication of washout tooling. Stratasys, Ltd. very recently presented a proprietary thermoplastic blend (ST-130) material for the creation of soluble tooling with FDM, which is chemically dissolved in an alkaline solution [27]. Binder jetting of sand is a proposed technique in which a watersoluble and temperature-resistant binder is deposited onto a sand bed, forming the slice of the three-dimensional (3D) tool. The tool is then sealed typically using spray-on coating. It is then overlaminated with the reinforcement material and cured [28].

Additive manufactured elements have also been employed as structural cores for composite sandwich applications. Nygaard et al. proposed to structurally grade sandwich core materials in a lengthwise direction to achieve the highest stiffness in the area of the concentrated load while gradually reducing the stiffness toward free boundary regions. The graded core material showed a reduced bending moment and deflections in the area of the load introduction [29]. Williams et al. investigated corrugated sandwiches using FDM, three-dimensional printing, and stereolithography to produce complex-shaped cores that were over-laminated in a wet-layup process with carbon fiber. Corrugated stereolithography cores seem to outperform flat designs in three-point bending, indicating that freedom of shape could be beneficial for enhanced functionalities [30]. Such functionalities may include defined snap-through instabilities in 3D-printed sandwich cores, which significantly enhance the energy-absorption capabilities [31].

1.3 Summary of Limitations of Existing Approaches. Traditional approaches require high manual effort and involve a high number of processing steps for the creation of the tool. As a consequence, lead times of such manual processes are long and the information about the geometry often is not digitally available [32]. Moreover, traditional techniques for washout-tool require machining equipment, a master mold, and additional steps for material preparation.

The recent approaches using AM can significantly reduce the lead times. However, material availability for autoclave-proved thermoplastics is very limited and expensive. Existing studies often use wet-layup processes where the resin is cured at 1 bar and room temperature only. The necessary material amount strongly increases with the entrapped volume of the tool to be produced. Moreover, for FDM chemical substances are required to dissolve the tooling material. The autoclave suitability for processes up to $120^{\circ} \mathrm{C}$ and 3 bar pressure is not yet proven on part level. Finally, binder jetting of sand does not allow to integrate functional design features for tooling assembly operations. Sand tools are brittle, which makes transport not convenient. Finally, the sealing is based on water, which might dissolve the water-soluble binder during spray-on [28].

To sum up, the potential for lead-time reduction of AM tooling has been shown. However, existing approaches are either not costefficient, or use proprietary materials, or are not autoclave suitable, and do not promote the spreading of AM tooling through design know-how in order to lower the entry barrier for such technologies.

This paper presents two approaches for the realization of complex-shaped hybrid composite structures.

In the first approach, structural AM cores with honeycombs and trusses were inserted during the layup and co-cured to form an integral, hybrid structure. The second approach uses a functional AM hull that is filled with a temperature-resistant curing support material. After curing, the filler material is removed to obtain a hollow CFRP structure. The behavior of the tooling under autoclave processing conditions was predicted through simulations. Hat-stiffener beams were fabricated and tested in three-point bending (3PB) to compare the approaches with a state-of-the art foam core reference.

The goal of this study is to provide comprehensive design and fabrication knowledge for the development of integrated lightweight structures with complex geometries by combining the advantages of AM and CFRP. The ultimate goal is to lower the entry barrier for such technological applications and to disseminate the necessary design and processing know-how.

The paper is organized as follows: Sec. 2 presents two approaches for co-curing AM elements in the autoclave layup process. In Sec. 3, the approaches are applied to hat-stiffener beams. Section 4 presents the numerical simulations and Sec. 5 the threepoint bending experiments. Section 6 discusses and Sec. 7 concludes that paper.

\section{Co-Curing Additive Manufactured Elements With Carbon Fiber-Reinforced Polymers in Autoclave Layup Processes}

This section presents two approaches for co-curing AM elements with CFRP in an autoclave layup process. First, an approach for structural cores made with AM is presented, including honeycombs and trusses. Second, an approach for washout tooling, making use of a thin functional AM shell, is proposed.

\subsection{Autoclave Co-Curing of Structural Additive} Manufactured Cores and Carbon Fiber-Reinforced Polymers. In this study, structural cores are defined as elements, which are inserted during the layup, provide the layup surface for the CFRP, and structurally support the part during curing and operation. The structural core remains in the final part and forms an integral hybrid structure with the CFRP.

The general manufacturing technique consists of a co-curing autoclave process. The novelty is the insertion of complex structural elements made by additive manufacturing during the layup process, which allows the realization of complex integral parts.

The general manufacturing route is shown in Fig. 1. Complex structural elements are produced using AM. The prepreg plies are removed from the refrigerator, thawed, and cut in the desired orientation to near-net shape. A base tooling is cleaned and treated with release agent. The prepreg plies are draped on the tooling. Then, the structural AM elements are positioned on the prepreg, and if required by design, pinned to the base tool. The remaining prepreg plies are placed on the structural AM element. The layup is vacuum bagged and the entire assembly is placed in the autoclave where the composite is co-cured and consolidated in one shot. After cooling, the bagging is removed and the part is demolded. Finally, postprocessing operations including trimming and surface finishing may be applied.

In the proposed processing route, the hybridization occurs $d u r$ ing the layup, as opposed to traditional processes where precured parts are joined to form a hybrid part.

2.1.1 Additive Manufactured Honeycomb Cores With Enhanced Functionality. Honeycombs are efficient elements for application as structural cores in sandwich structures. However, the geometric freedom of traditional aramid or aluminum honeycombs cores is limited by the manufacturing technology, which yields flat or singly curved sandwich panels.

With additive manufacturing, the honeycomb cell geometry can be replicated and extended with additional functionalities with the goal to simplify the processing and the performance of AM-CFRP sandwiches. In the following, two concepts for AM honeycombs 


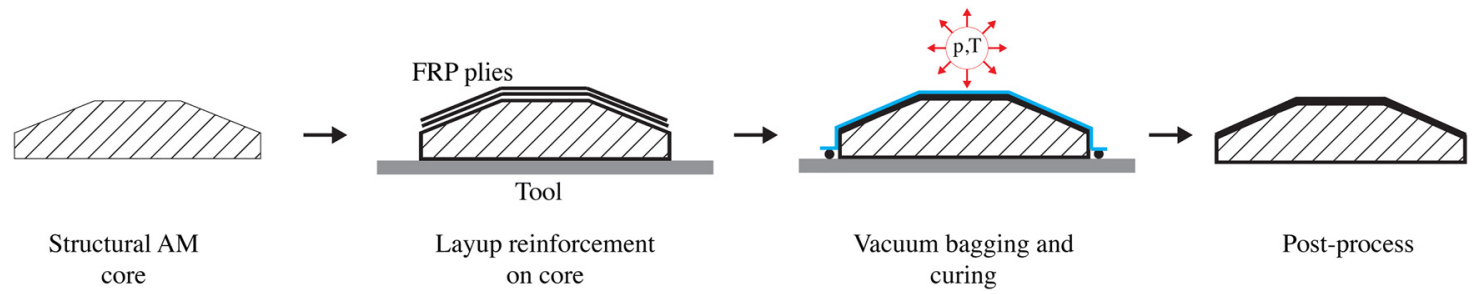

Fig. 1 Schematic processing route for the manufacturing of a hybrid AM-FRP structure using a structural AM core that is over-laminated with FRP and cured

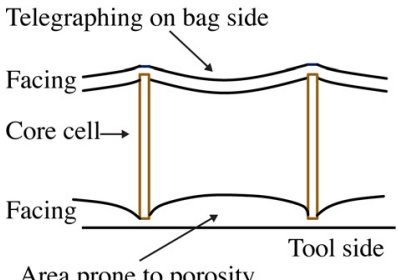

Area prone to porosity

and delaminations

(a)

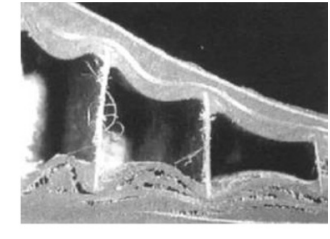

Fig. 2 Schematic (a) and section view and $(b)$ of telegraphing effect in co-cured honeycombs adapted from Ref. [34,35]

are presented that address two issues with conventional honeycomb sandwich structures.

The first aspect is telegraphing of co-cured honeycomb sandwich structures (Fig. 2). Telegraphing or pillowing is an undesired effect during the co-curing of sandwich structures where the reinforcement facings deform within an individual cell as a result of a too big cell size and if the applied processing pressure is too high [33]. The resulting out-of-plane deflection of the fibers may reduce the mechanical properties of the composite by as much as $30 \%$ compared to a bonded sandwich structure [34]. The out-ofplane deflection especially reduces the compression properties of the composite. On the tool side, migration effects can occur during the curing of honeycomb sandwich panels. Migration is a movement of the core or the prepreg from the desired position and can lead to deflected core cells, delamination, and porous facings.

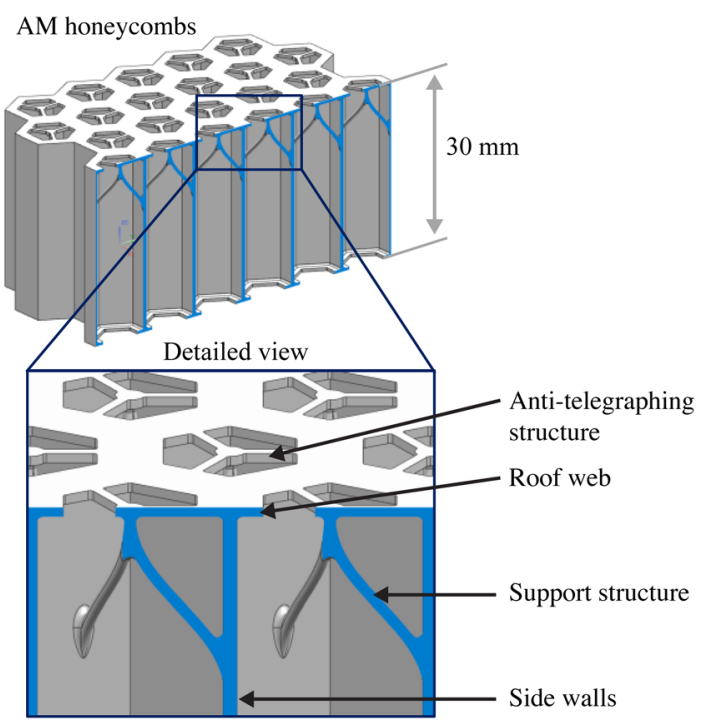

Fig. 3 Additive manufactured honeycombs with integrated antitelegraphing structure and roof webs for enhanced bonding to the face sheets
This effect can be addressed with AM by integrating antitelegraphing structures on top of the AM honeycomb cells (Fig. 3). In this example, the antitelegraphing structure consists of three beams that are supported in the center of the cell. The support structure is connected to the cell walls in order to avoid a length that is critical for kinking. The antitelegraphing structure can be optimized for different processing pressure loadings and cell sizes to minimize the deflection of the facings during curing.

The second aspect concerns the adhesive interface between the facings and the cell walls. Traditional sandwich structures may be co-cured or use an adhesive layer to create a resin fillet between the core and the facings during the curing stage. The ideal fillet is equally large and thoroughly wets the cell walls. The degree of filleting is a major criterion for the strength of the assembly [35]. However, the fillet development during processing is difficult to control and different undesired types of fillets may result. Moreover, the inspection of fillet development in the cured part is difficult. Finally, numerical modeling of the fillet is challenging as a consequence of the unknown geometry.

In traditional manufacturing techniques, the core-facing bonding is influenced by the processing parameters, whereas with AM, the bonding can be influenced through design. The vertical cell wall in Fig. 4 is extended by a radius and a roof web, which potentially enhances the load transfer between the facing and the core. The horizontal bonding surface area is increased and a preferable lap-shear loading condition is formed at the bonding interface, instead of a bending loading type. The facings are co-cured to the roof webs which also serve as layup surface. No adhesive is therefore required, which allows to reduce the number of processing steps.

2.2 Washout Tooling With Functional Additive Manufactured Hull and Temporary Filler Material. This section introduces a novel approach for washout tooling using a functional hull made with AM (Fig. 5). The underlying idea of the approach is to separate the shape-giving function from the structural curing support. In this approach, a thin hull with integrated functionalities is designed and produced with AM. The hull is filled with a temperature- and compression-resistant filler

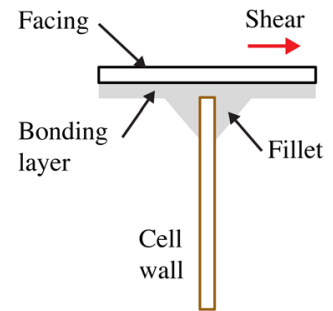

(a) Conventional facinghoneycomb interface

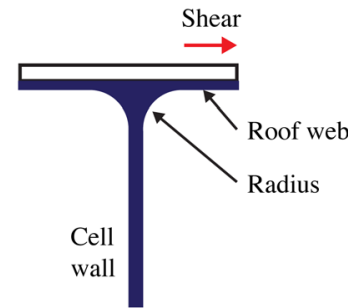

(b) AM honeycombfacing interface
Fig. 4 State-of-the art facing-honeycomb interface using a bonding layer with a difficult filler inspection (a), additive design concept and $(b)$ with horizontal bonding surface for cocured interface and ideally better shear load introduction 


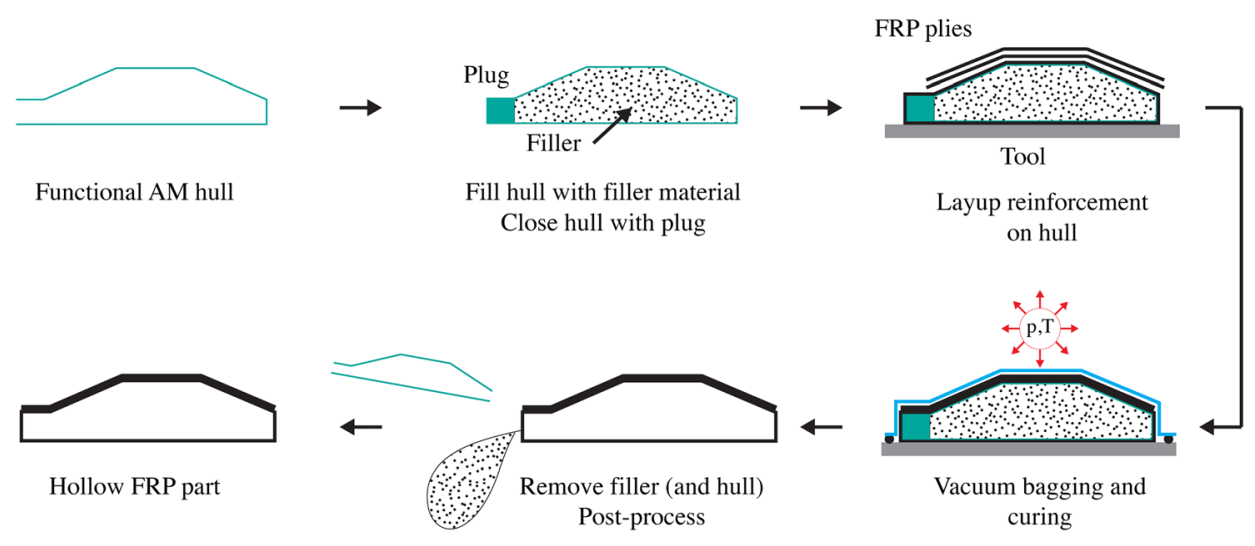

Fig. 5 Processing route for the manufacturing of a hybrid AM-FRP structure using a functional hull made with $\mathrm{AM}$, and a temperature-resistant filler material

material, and once filling is complete, it is closed using a plug. The hull is sealed using an epoxy resin that preferably cures at room temperature and has a glass transition range, which is higher than the temperature used in the autoclave curing cycle. In the next step, the traditional prepreg layup technique is applied, which includes the layup of the near net-shape reinforcement material and vacuum bagging. The assembly is cured, e.g., in an autoclave. After curing, the vacuum bag is removed. The plug is removed and the filler material is washed or trickled out.

Dependent on the application, the hull may be fully or partially removed. Additional functionalities (e.g., connection elements, load-bearing support structures) may be integrated into the remaining part of the hull, which may be necessary in the operation of the composite part. In the case of hull removal, release agent should be applied after sealing. Also, the hull may include integrated breaking points to facilitate mechanical removal of the hull from the cured composite.

The filler material is ideally selected according to the following criteria, which are explained in the following:

- Flowability

- Temperature resistance

- Compression resistance

- Ecological removal

- Solubility

- Cost-efficiency

When the filler material is poured into the functional hull, it should easily trickle into the corners and undercuts in order to completely fill the internal volume of the hull. The use of a vibrating table may help in reaching an equal distribution of the filler. The filler material should be temperature-resistant and possess a glass transition range and/or a melting temperature, which is higher than the curing temperature. Moreover, the filler material should exhibit a high compression modulus in order withstand the processing pressures which are required to consolidate the laminate. An ecological way of removing the filler material after curing is desired, preferably using water instead of chemical solutions. Finally, a cost-efficient filler is desired to provide costcompetitive tooling solutions for larger structures.

\section{Design of Hybrid Stiffeners with Additive Manufacturing and Carbon Fiber-Reinforced Polymers}

In this section, the proposed approaches are applied to hatstiffener beams. The design space, the materials, and the reference hat-stiffener design are presented.

3.1 Design Space and Materials. The reference application is a stiffener that is applied to a panel structure. The bending

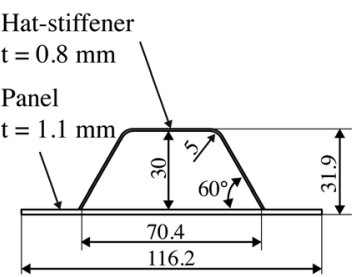

(a)

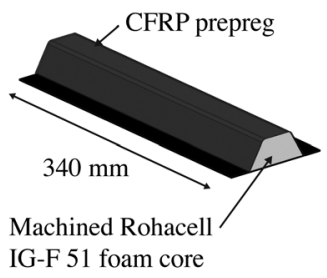

(b)
Fig. 6 Design space (a) and reference hat stiffener consisting of a machined foam core and a CFRP prepreg layup (b)

stiffness of the stiffener is an important indicator for the performance of the panel, which is why the stiffener is considered as a beam structure in three-point bending.

The reference geometry displayed in Fig. 6(a) consists of an omega-shaped hat stiffener that is either co-cured or co-bonded to a flat panel with a defined stiffener length of $340 \mathrm{~mm}$, a total height of $31.9 \mathrm{~mm}$, and a total width of $116.2 \mathrm{~mm}$. The core exhibits a height and a top width of $30 \mathrm{~mm}$ each, a bottom width of $70.4 \mathrm{~mm}$, and sides that are inclined at an angle of $60 \mathrm{deg}$ with a transition radius of $5 \mathrm{~mm}$.

The core is laminated with carbon fiber-reinforced prepreg material using unidirectional SGL Sigratex CE 1007-150-38 with a ply thickness of $0.14 \mathrm{~mm}$ and an areal weight of $150 \mathrm{~g} / \mathrm{m}^{2}$, together with a SGL Sigratex twill fabric CE 8201-200-45S with a ply thickness of $0.19 \mathrm{~mm}$ and an areal weight of $200 \mathrm{~g} / \mathrm{m}^{2}$.

To compare the performance of the cores only, the CFRP material, layup, and orientation are defined for all samples as follows: The stiffener profile uses a (45f/0/0/0/45f) layup with the fabric on top and on the bottom, and with unidirectional (UD) reinforcements in the middle, resulting in a total stiffener laminate thickness of $0.8 \mathrm{~mm}$. The layup of the panel consists of a (45f/0/0/45f/ 0/0/45f) layup using UDs and fabrics resulting in a total thickness of $1.1 \mathrm{~mm}$.

The design space is defined by the maximum core height, width and length, as well as the layup and the material. In order to show the potentials of AM, core designs can be of a lower height if structural integrity is guaranteed.

3.2 Reference Design. The reference design depicted in Fig. 6(b) consists of a hat stiffener with a machined Rohacell ${ }^{\circledR} 51$ IG-F foam core, a structural support material widely used in applications ranging from automotive to industrial [36]. The total weight of the design amounts to $186 \mathrm{~g}$, with the foam core weighing $30 \mathrm{~g}(16 \%)$ and the CFRP prepreg weighing $156 \mathrm{~g}(84 \%)$. The reference samples showed first failure at $757 \mathrm{~N}$ and maximum 


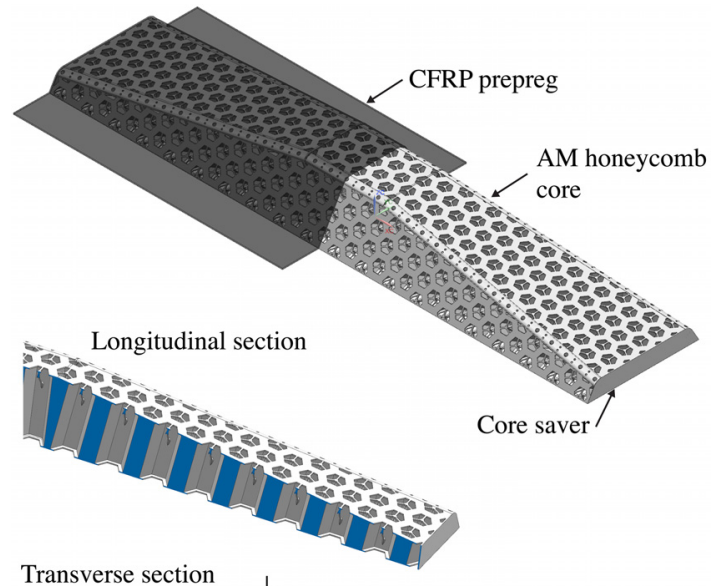

Transverse section

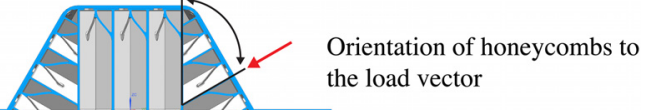

Fig. 7 Design concept for a CFRP hat-stiffener beam with AM honeycomb core

load at $2.2 \mathrm{kN}$. The first failure load is used as a design load for the three-point bending.

3.3 Honeycomb Design. The AM honeycomb core concept from Subsection 2.1.1 is applied to a hat-stiffener beam geometry shown in Fig. 7. Additive honeycombs with integrated antitelegraphing structure are regularly arranged in the design space. The cell geometry consists of a cell wall thickness of $0.35 \mathrm{~mm}$ and $0.3 \mathrm{~mm}$ in the load introduction area and in other areas, respectively. The roof web has a thickness of $0.5 \mathrm{~mm}$ and the support structures designed as splines have a diameter of $0.6 \mathrm{~mm}$. The cell width amounts to $10 \mathrm{~mm}$.

The unit cell density amounts to $184 \mathrm{~kg} / \mathrm{m}^{3}$ and $162 \mathrm{~kg} / \mathrm{m}^{3}$ in the area of the load introduction and elsewhere, respectively.

The stiffener has chamfered edges to remove material in unloaded areas, which is easily possible with the freedom of design AM has to offer. The core height decreases from $30 \mathrm{~mm}$ in the area of the load introduction to $10 \mathrm{~mm}$ at the longitudinal endings.

A significant design feature on part level is the free orientation of the honeycomb unit cells, which are oriented according to the occurring load. In this case, the cells are oriented perpendicularly to the outer surface of the stiffener to bear the autoclave processing load. As a consequence, edge rails, which are used to protect the core from collapse as a result of lateral processing load, are dispensed in longitudinal direction of the profile. However, core saver, which consists of an integrated edge rail, is employed at the end of the profile. The core savers are removed mechanically after curing and protect the core from collapse during processing.

3.4 Truss Design. The AM truss design concept combines lightweight elements including trusses and beams on detailed

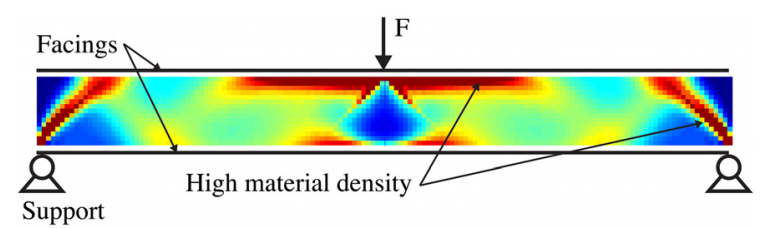

Relative material density: 0

Fig. 8 Relative material density in a longitudinal section of a sandwich core under three-point bending loading. Based on Ref. [38] using a penalty factor $p=1$. level. The structural core is designed for two load cases: threepoint bending and autoclave processing.

Figure 8 shows the result of an iterative optimization approach, which is based on generalized optimality criterion. In this approach, which is derived from laminate optimization, a constant strain energy density across the overall cross-section by adapting the material density is reached. The approach is applied to a longitudinal section of a core of a sandwich structure in three-point bending. A penalty factor $p=1$ is used, allowing intermediate densities between 0 and 1 for a converged solution. It has been shown that a solution with $p=1$ is favorable than one where $p>1$ [37] and therefore the approach may serve well as a basis for a truss core design. A more detailed description of the algorithm can be found in Ref. [38].

Figure 8 shows that a high material density is required near the load introduction, where a large horizontal and two diagonal regions of dense materials have developed. Beneath the load, the required relative material density is low. A second area of interest is the supports, where a high relative material density is required. It should be noted that the simulation is restricted to a twodimensional design space and is a preliminary result. Nevertheless, the simulation supports the designer in finding an appropriate design.

Figure 9 shows the embodiment of the concept using structural lightweight elements. The blue structure consists of sheet-like elements and hollow trusses, which are combined in one part to bear the three-point bending load. An iterative approach between computer aided design modelling and numerical verification is used to embody the optimization result presented above into an AM design. For example, hollow diagonal trusses, which transfer the transverse loading into the bottom CFRP panel, are employed in the area of the load introduction area. Moreover, the material thickness of the core is increased in the horizontal layer of the load introduction. Finally, a hollow truss-like structure is used to transfer the load into the supports.

The blue structure of the core is superimposed with the grey structure, which bears the pressure load during autoclave processing. The autoclave load is a surface load, which acts on the uncured prepreg. Regular grids and rods are used to withstand the pressure loading. The grid consists of T-beams, which minimize the deflection as a result of the processing pressure and provide the necessary layup surface for the CFRP plies. The T-beams are distanced in such way to minimize the telegraphing effect for the selected processing parameters. The grid is supported by hollow

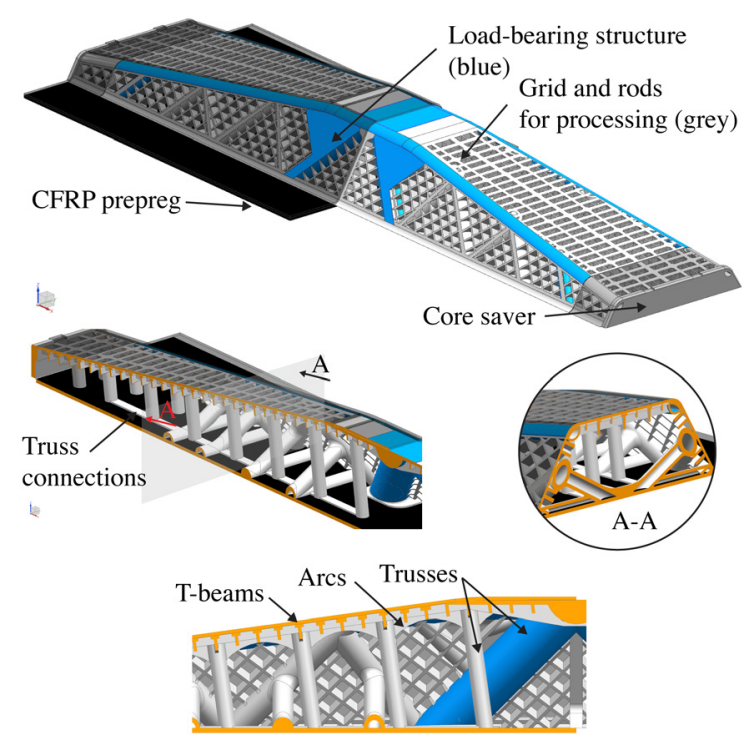

Fig. 9 Design concept for a hat stiffener with CFRP and an AM core using structural lightweight elements 
trusses at spatially defined distances. Arcs connect the trusses in lengthwise direction. On the sideward surfaces of the hat stiffener, a simple grid structure, which is supported by larger hollow trusses, is used to avoid process-related indentations. It should be noted that the trusses are oriented perpendicularly to the side planes to support the structure. The trusses are connected in the center of the profile for mutual support (see section view). The effect of prepreg mitigation, as mentioned in Sec. 2, is minimized in the bottom facings by connecting the individual trusses.

3.5 Salt Core Design. Figure 10 shows a design concept for an AM-CFRP hat stiffener which is based on the functional AM hull for washout tooling presented in Sec. 2.2.

The underlying idea of the approach is to separate the functions of (i) shape, (ii) structural curing support, and (iii) load-bearing support. A thin functional hull with a thickness of $0.5 \mathrm{~mm}$ is manufactured using selective laser sintering (SLS) to provide the layup surface and the shape of the structure. The functional hull can be made using various AM technologies, however, to fully use the design potential, a technology that allows distinct design features to be produced, should be selected. Such design features can include joining and connection elements to assemble separate parts of the hull in order to cope with the limited building envelope of the selected AM system. The hull is filled with commercially available salt which is used as a structural curing support. Salt has a high compression modulus, a melting temperature of up to $800{ }^{\circ} \mathrm{C}$ [39], is inexpensive, widely available, and chemically dissolves in water. A SLS plug is used to enclose the inner volume of the functional hull prior to lamination. After curing, the salt is dissolved in water.

In this concept, diagonal hollow trusses are used as loadbearing supports of the AM-CFRP stiffener during the three-point bending load case. The design freedom of AM allows to integrally produce the shape-giving hull with the load-bearing support.

3.6 Manufacturing. At least two specimens are produced and tested for each design. The general manufacturing route comprises the steps described below, while several manufacturing impressions are shown in Fig. 11.

Selective laser sintering of the cores: the structural cores and the functional hull were produced on a DTM Sinterstation $2500_{\text {plus }}$ with a building area of $300 \times 260$ from commercially available DuraForm HST composite powder material developed by 3D systems [40]. The compound is a dry blend based on Polyamide 12 with a filler content of $25 \mathrm{wt} \%$ of wollastonite fibers. The fibers act as a reinforcement in order to increase the mechanical and thermal properties of the material [41]. The parts are produced using a part-bed temperature of $170^{\circ} \mathrm{C}$, a laser power of 48

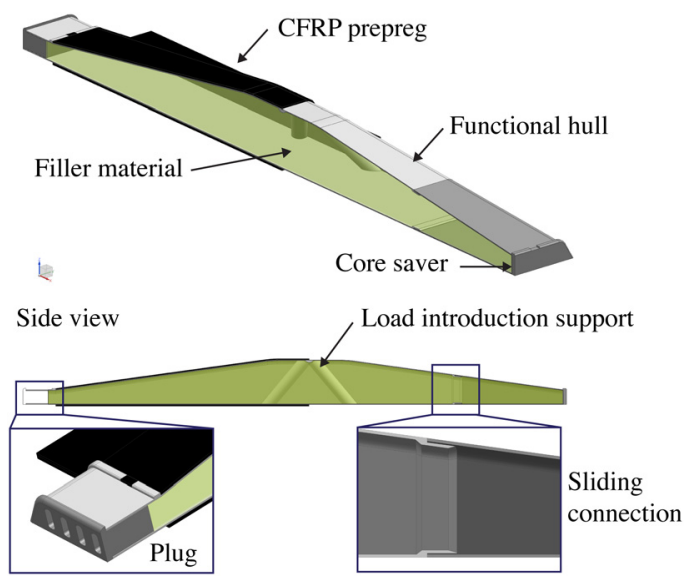

Fig. 10 Design concept for a CFRP hat-stiffener beam with functional hull made by $A M$ and a temporary filler material
$\mathrm{W}$, a scan speed of $10 \mathrm{~m} / \mathrm{s}$, and a hatch distance of $0.24 \mathrm{~mm}$. As a consequence of the limited building envelope, the sintered core elements are bonded using a high temperature epoxy adhesive. Prior to the CFRP layup, the 3D-printed shell of the salt core design is filled with commercially available table salt, which is compacted by shaking and tapping to ensure sufficient filling.

Layup and autoclave co-curing: the AM elements were inserted during the layup and co-cured in an autoclave prepreg process as described in Sec. 2. The autoclave was heated at a rate of $1 \mathrm{deg} /$ min up to $100^{\circ} \mathrm{C}$, held at $100^{\circ} \mathrm{C}$ for $2 \mathrm{~h}$, and was then cooled down to room temperature at a rate of $1 \mathrm{deg} / \mathrm{min}$. The total pressure applied to the layup during curing consisted of 1 bar vacuum and 1.5 bar autoclave pressure.

Post-processing: This step includes the demolding of the part from the tooling plate and the trimming of the edges and the temporary curing aids (e.g., core saver) to obtain the final contour. While the structural AM cores remain in the hybrid co-cured part, the salt is removed after curing.

3.7 Weight. Figure 12 shows the laminate, core and overall weights of the specimens. The structural cores were weighed prior to lamination and after curing.

The laminate weight varies between $151 \mathrm{~g}$ and $156 \mathrm{~g}$ with an average weight of $153.5 \mathrm{~g}$. The variation of the laminate weight is probably attributable to process-related resin flow effects. The core design can have a significant impact on the overall structural weight. The weight of the foam core of the reference design amounts up to $30 \mathrm{~g}$ which corresponds to $16 \%$ of the overall weight, while the honeycomb core weighs $74 \mathrm{~g}$ or $33 \%$, the truss core weighs $84 \mathrm{~g}$ or $35 \%$ and the weight of the functional hull amounts to $25 \mathrm{~g}$ or approximately $14 \%$.

The salt core design is a weight competitive approach for the selected geometry. The authors estimate that approximately $20 \mathrm{~g}$ of the core weight are associated with the functional hull, and approximately $5 \mathrm{~g}$ are required for the diagonal trusses supporting the hybrid stiffener during three-point bending. In the salt core concept, the core weight decreased by approximately $16 \%$ compared to the foam core and the weight reduction would be more significant if the functional core would be removed mechanically after curing, leaving only the load-bearing trusses in the hollow structure.

\section{Numerical Simulations}

4.1 Numerical Models. Two finite element simulation models are developed in ABAQUS CAE 6.14-1; namely a process model to predict the mechanical response of the structure subjected to the processing pressure, and a load model for the structural response under three-point bending. Both simulations are quarter models with symmetry conditions to replicate the whole structural behavior. Both models use solid C3D10-tetrahedral elements to represent the AM core and S4R conventional shell elements to model the CFRP reinforcements.

Linear elastic simulations using finite-element-method were conducted to identify the weakness of the designs. Linear elastic models are only valid in the linear elastic range of the force-displacement diagram of a specific design. Therefore, an assessment up to the first failure (end of linear elastic range) can be made.

The designs are considered to be valid if the elastic strain EE for the composite, the von Mises stress of the AM core and the displacements of the AM core are lower or equal to the values of the reference design at a load of $757 \mathrm{~N}$, which corresponds to the experimentally determined first failure load.

The design allowables are shown in Table 1, and the material properties are summarized in the Appendix.

4.1.1 Process Model. The process model shown in Fig. 13(a) simulates the processing conditions, autoclave and vacuum pressure acting on the outer surface of the structure at a temperature 

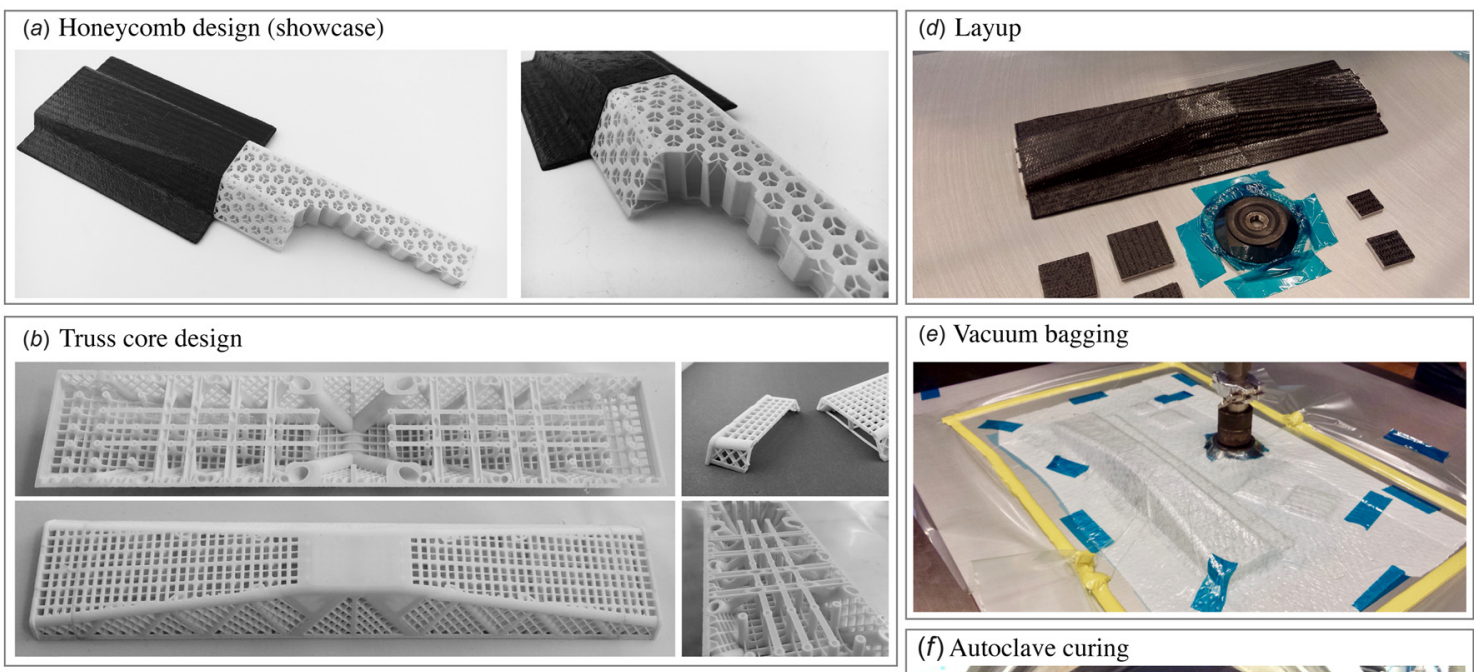

(c) Salt core design
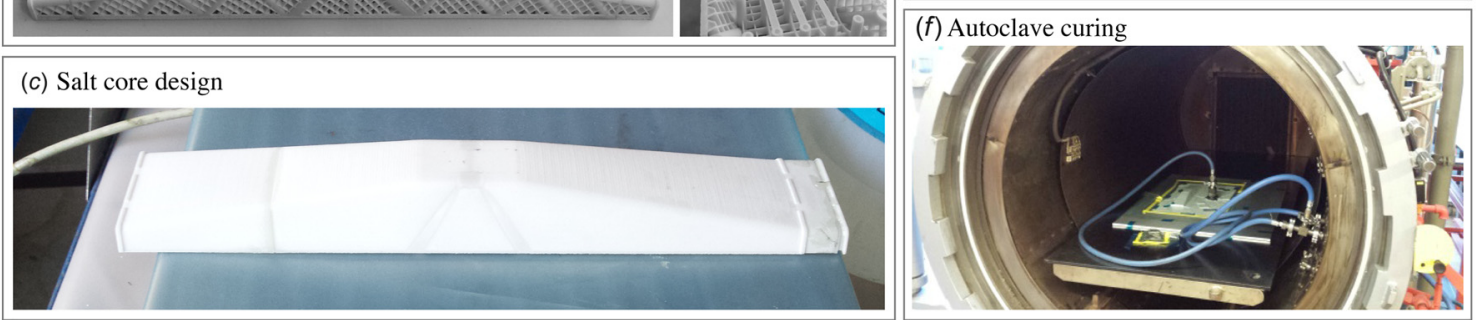

Fig. 11 Manufacturing impressions: first the honeycomb (a), truss $(b)$, and salt $(c)$ cores are produced with selective laser sintering. Then, CFRP layup is applied (d), the assembly is vacuum bagged $(e)$ and cured in the autoclave $(f)$.

of $100^{\circ} \mathrm{C}$. At the beginning of the curing stage, the reinforcement material is wet and does not fully contribute to the overall stiffness of the profile until the gel point is reached. Therefore, a reduced prepreg stiffness of $50 \mathrm{MPa}$ is used in the simulation. A pressure load of $2.5 \mathrm{bar}$ is applied. A maximum displacement of $0.5 \mathrm{~mm}$ is used as failure criteria. The material data for DuraForm $\mathrm{HST}$ at $100^{\circ} \mathrm{C}$ is taken from Ref. [42].

4.1.2 Three-Point Bending Load Model. The 3PB load model shown in Fig. 13(b) consists of the hat stiffener, a steel roller, and the supports. The support is fixed with an encastre condition. The only displacement allowed for the central roller is in the $z$ direction. The AM core is tied to the CFRP laminate. The contact of the stiffener with the central roller and the supports is modeled using contact interaction properties (tangential frictionless

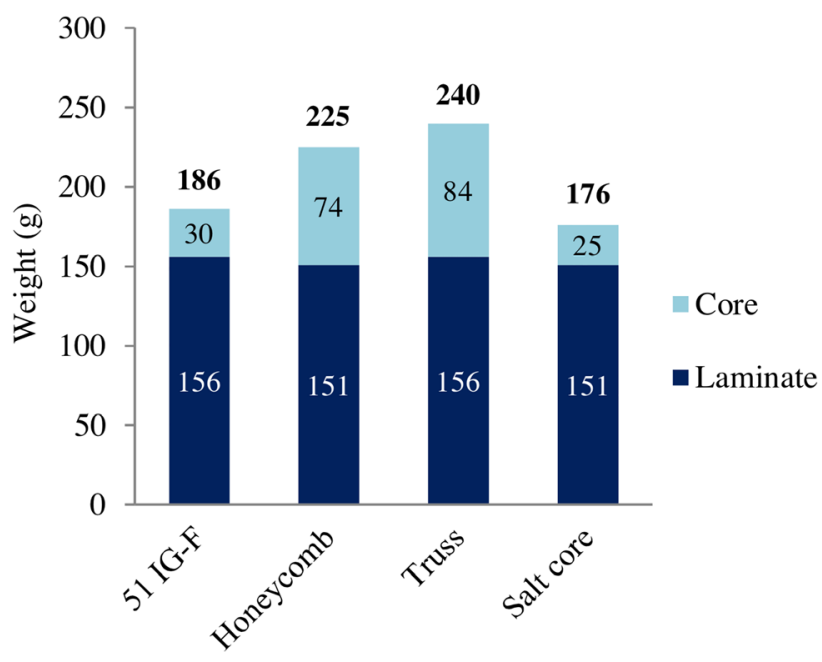

Fig. 12 Weight comparison contact). A total force of $757 \mathrm{~N}$ is introduced into the stiffener, which represents the first failure load of the reference foam core. An equivalent pressure of $206.4 \mathrm{MPa}$ is thus applied on top of the quarter surface of the roller. The failure criteria for the core are a maximum stress of $39 \mathrm{MPa}$ which corresponds to the yield strength of the HST DuraForm [40]. The design allowables for the CFRP are strains exceeding $1.2 \%$.

The maximum strain criterion being a simple and direct way to predict failure of composites is used in the following. The criterion considers that the CFRP fails when the strain exceeds the respective allowable (CITE MAX STRAIN), or formulated as a margin of safety $\psi$

$$
\psi=\min \left(\frac{\epsilon_{\max }}{\epsilon_{1}}, \frac{\epsilon_{\max }}{\epsilon_{2}}, \frac{\epsilon_{\max }}{\epsilon_{12}}\right)-1
$$

with $\epsilon_{\max }=1.2 \%$ being set as a fairly conservative allowable derived from the material properties in compression and tension in fiber, transverse and shear directions, and $\epsilon_{1}, \epsilon_{2}$, and $\epsilon_{12}$ being the occurring strains in fiber, transverse and shear directions of the critical ply.

4.2 Reference Design. The critical load for the foam core is the three-point bending. At the breaking load of $757 \mathrm{~N}$ the reference design shows excessive stresses in the foam core and strains in the laminate (Fig. 14(a)). The region of excessive load is located at the edge to the side wall of the stiffener profile. The

Table 1 Design allowables

\begin{tabular}{lccc}
\hline \hline Entity & Parameter & Value & Unit \\
\hline Rohacell IG-F 51 & Compressive strength & 0.9 & $\mathrm{MPa}$ \\
CFRP UD \& Fabric & Laminate strain & 1.2 & $\%$ \\
DuraForm HST & Yield stress at room temperature & 39 & $\mathrm{MPa}$ \\
Hat stiffener & Displacement & 0.5 & $\mathrm{~mm}$ \\
\hline
\end{tabular}




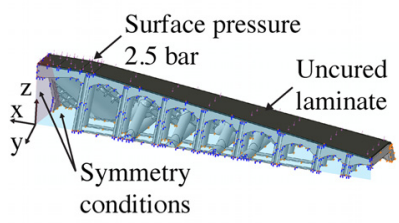

(a) Process model

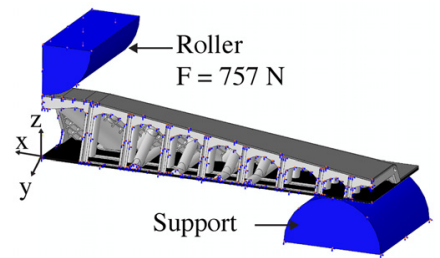

(b) Three-point bending model

Fig. 13 Process (a) and three-point bending (b) simulation model

stresses in the foam core amount up to $1.58 \mathrm{MPa}$, thus exceeding the compressive strength of $0.9 \mathrm{MPa}$. The strain in the laminate amounts up to $1.43 \%$, exceeding the design allowable of $1.2 \%$. These results suggest that the area of the load introduction is critical in three-point bending. Also, it is assumed that the low compressive strength of the foam core is the limiting factor.

4.3 Honeycomb Design. Figure 14(b) shows the displacements of the chamfered honeycomb core under a processing pressure of 2.5 bar. In general, the displacements are uncritical; however, the displacements increase in large exposed surface areas. Higher displacements are reported in the center of the profile, where the area of the sides contributes to the overall displacement. The maximum is reached in the antitelegraphing crosses where it amounts to $0.078 \mathrm{~mm}$, which is below the design allowable of $0.5 \mathrm{~mm}$.

The von Mises stresses and the laminate strain is assessed for the three-point bending loading. In general, the von Mises stresses are uncritical in the AM honeycomb core. The maximum is reached very locally in the load introduction area where the roller is in contact with the specimen. Also, the laminate strains highlight the local effect in the load introduction. The strains amount up to $0.036 \%$ which is below the allowable of $1.2 \%$.

4.4 Truss Design. Figure 14(c) shows the stresses in the principal stress design at a processing pressure of 2.5 bar. Elevated stress levels are found in the lightweight grid, in the top, and in the sides of the center. The lightweight grids are optimized for the stress distribution of 8.5 MPa. A single stress outlier amounting to 69.3 $\mathrm{MPa}$ is found in a highly distorted element.

Regarding the displacement in the truss core at a processing pressure of 2.5 bar, the simulation reveals that the longitudinal grid structure is significantly loaded compared to the sideward surfaces. The maximum displacement is found in a beam in the grid structure and amounts to $0.208 \mathrm{~mm}$ which is below the allowable of $0.5 \mathrm{~mm}$.

The 3PB loading results in a more local loading of the structure with a stress peak reaching up to $15.61 \mathrm{MPa}$ in the core and laminate strains reaching up to $0.357 \%$ in the load introduction edges.

The laminate strains reveal minor strain peaks in the area of the supports and at the transition from the horizontal hat shape to the longitudinal slope. All values are uncritical.

4.5 Salt Core Design. Figure $14(d)$ shows the von Mises stresses in the functional hull and the laminate strain for the threepoint bending loading. The AM core is loaded in the area of the load introduction and the section view reveals stresses in the diagonal trusses. In the lower area of the struts, the design freedom was constrained by the requirement of powder removal which is why the material utilization could not be optimized in this area. The maximum von Mises stresses of $27.39 \mathrm{MPa}$ are found in the edge of the load introduction due to roller contact. The salt core design exhibits higher material utilization of the laminate, compared to the reference and the honeycomb designs. However, the strain peak of $0.528 \%$ is found in the load introduction edge.
Minor strain peaks are found in the diagonal struts, and the supports. The laminate strains do not exceed a value of $1.2 \%$.

Based on the numerical simulations, it is assumed that all design concepts exhibit first failure loads that are higher than $757 \mathrm{~N}$.

The simulation results clearly show the potential of the idea of separating shape, curing and load-bearing function. During processing, the displacements are fairly well distributed over the entire curing structure (e.g., honeycombs, grids, and trusses), whereas high stresses are found in the load-bearing structure (e.g., diagonal trusses and load introduction area), when a single load is applied on the structure. This approach could be considered as an extension of design for manufacturing for structural cores leveraging the freedom of AM.

\section{Experiments}

5.1 Three-Point Bending Tests. The specimens were mechanically tested in three-point bending on a 1494 Zwick universal testing machine with a load cell of $10 \mathrm{kN}$ at the Swiss Federal Laboratories for Materials Science and Technology (EMPA). All tests were conducted at a roller speed of $5 \mathrm{~mm} / \mathrm{s}$. The test was stopped whenever a decreasing force over a displacement of $2 \mathrm{~mm}$ was reached. The supports were placed at a distance of $300 \mathrm{~mm}$ and featured a diameter of $50 \mathrm{~mm}$ (Fig. 15).

5.2 Force-Deflection Diagram. Figure 16 shows the force-displacement $(\mathrm{F}-\mathrm{d})$ diagram of representative hat-stiffened beams tested in three-point bending. The first failure and the maximum breaking load (encircled in the figure) are key indicators for the mechanical load capacity of continuous FRP structures. The first failure is manifested by a kink in the F-d curve which represents a loss in stiffness, while the maximum force corresponds to the highest value during the measurement.

In general, the samples pass through the following critical stages of the loading procedure: The flat section of the F-d curve near the origin is a setting effect just after initial loading, followed by a linear-elastic range. First failure occurs at the end of the linear-elastic range. The load may increase with subsequent local failure effects that reduce the stiffness until the maximum breaking load is reached.

All samples outperformed the reference design in terms of first failure and maximum breaking load.

The first failure of the reference profile is marked by a kink at (1) in the linear-elastic section of the F-d curve at the force-displacement coordinates $(\mathrm{F}, \mathrm{d})$ of $(757 \mathrm{~N} ; 0.64 \mathrm{~mm})$. The central roller induces a damage on top of the side edges, while the middle is deflected downward. From this point on, the plies subsequently failed until a combination of the compressive strength of the foam core and the lower CFRP panel was measured. The force reached the maximum value of $2200 \mathrm{~N}$ at a displacement of $5 \mathrm{~mm}$ (2). The first failure of the honeycomb designs is found at (3001 $\mathrm{N} ; 1.73 \mathrm{~mm})$ and the maximum load is observed at $(5328 \mathrm{~N} ; 3.5$ $\mathrm{mm})$. The truss design showed the first failure at $(4029 \mathrm{~N} ; 2.29$ $\mathrm{mm})$ and maximum load at $(6368 \mathrm{~N} ; 4.17 \mathrm{~mm})$. The linear elastic range of the salt core showed the first failure at $(2808 \mathrm{~N}$; 
$1.99 \mathrm{~mm}$ ), followed by a quasi-linear decrease in the force until the abrupt failure at $(4180 \mathrm{~N} ; 4.01 \mathrm{~mm})$.

Figure 17 shows the failure locations of selected samples. All samples failed at the top of the profile at the load introduction which was expected from the simulation results. All specimens exhibit laminate failure in the top facings in the area of the load introduction. The salt core design failed at the interface of the diagonal trusses to the functional hull, where the diagonals separated from the outer shell. The bottom panel remained intact for all specimen.
5.3 Specific Failure Load and Stiffness. Figure 18(a) compares the first and the maximum failure load to the total weight of the hat stiffeners. The mechanical properties of all designs increased significantly. For example, the first failure load increased by $432 \%$ for the truss design, by $296 \%$ for the honeycomb and by $271 \%$ for the salt core approach. Also, the maximum load increased by $190 \%, 142 \%$, and $90 \%$ for the truss, honeycomb, and salt core design, respectively.

The bending stiffness of the profiles is assessed experimentally from the linear range of the force-deflection diagram according to

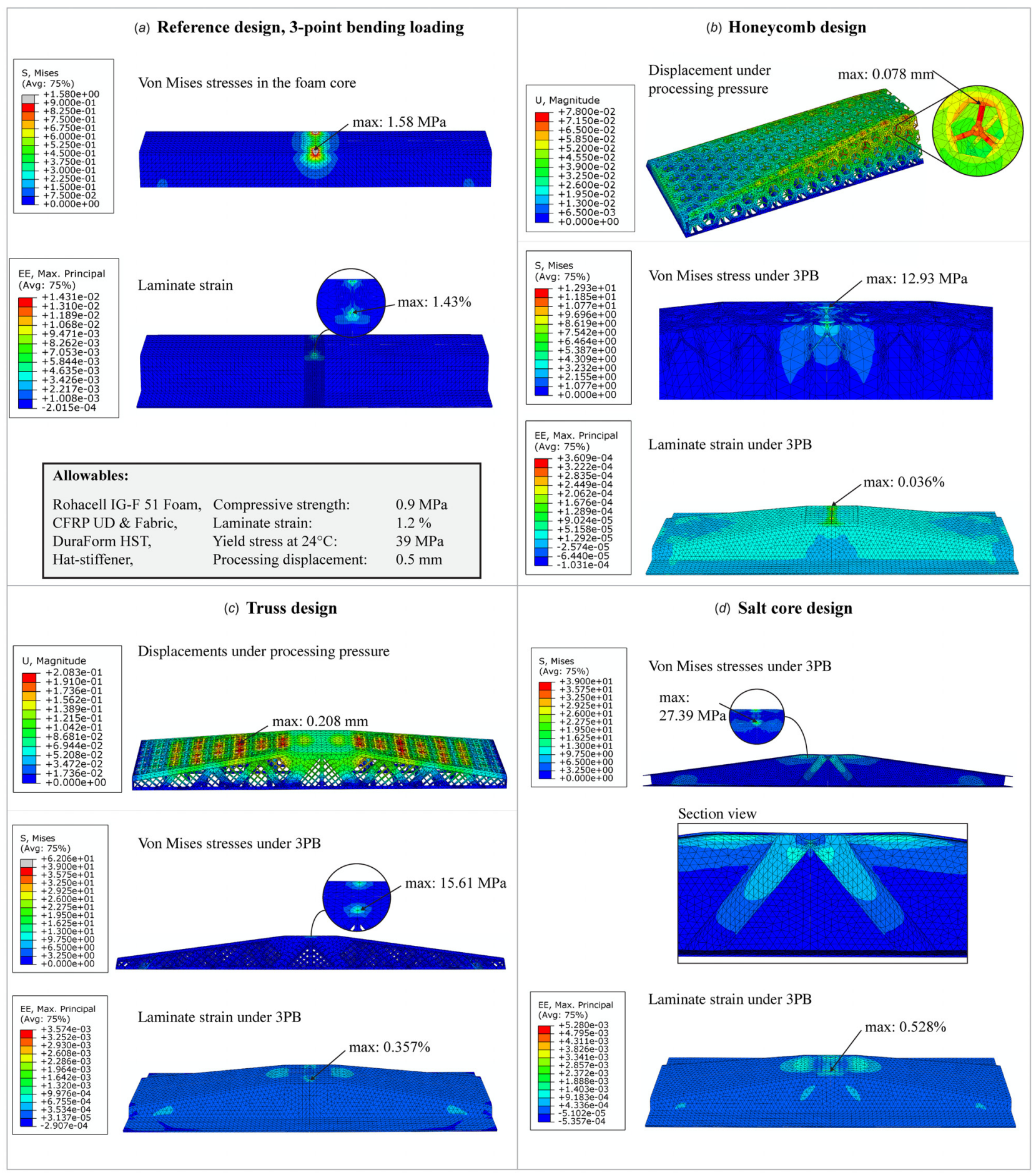

Fig. 14 Numerical results for (a) reference, $(b)$ honeycomb, (c) truss, and ( $d$ ) salt core design for relevant load cases. Results show fairly homogenous distributed displacements during processing loading for $(b)$ and $(c)$ and significantly reduced laminate strains and Von Mises stresses for the three-point bending loading in AM core designs. 


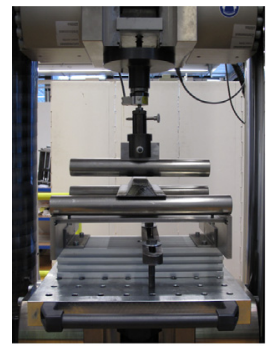

(a)

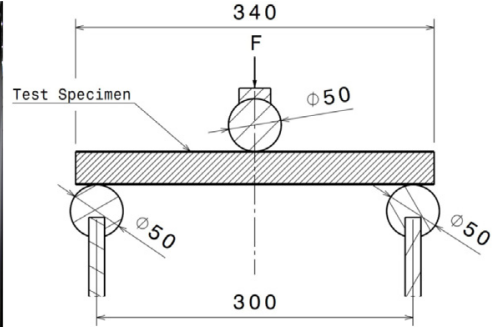

(b)
Fig. 15 Three-point bending test setup at EMPA

$$
K=\frac{F_{0.5}-F_{0.2}}{w_{0.5}-w_{0.2}}
$$

where $K(\mathrm{~N} / \mathrm{mm})$ is the stiffness of the profile in bending, $F_{0.5}$, $F_{0.2}$ are the forces and $w_{0.5}$ and $w_{0.2}$ are the deflections at $50 \%$ and $20 \%$ of the first failure load [43].

The bending stiffness increased for all specimens (Fig. 18(b)) by $45 \%, 34 \%$, and $12 \%$ for the truss, the honeycomb and the salt core design. Refer to Table 2 for a complete list.

5.4 Microstructural Characterization. The introduction of a novel process technique requires experimental verification of critical aspects regarding the quality of the structure. In this paper, these aspects include fiber volume and void content of the laminate as a result of comparatively low curing temperature and pressure. Moreover, the interface of the CFRP to the AM elements is of particular importance for the integrity of load-bearing hybrid lightweight structures. These parameters are assessed through microstructural characterization.

Polished samples were prepared with polishing resin and grinded using a Struers Abramin grinding machine. The fiber volume content $v_{f}$ of the laminate is assessed analytically using the following formula:

$$
v_{f}=\frac{\frac{\mathrm{wt} \%_{f}}{\rho_{f}}}{\frac{\mathrm{wt} \%_{f}}{\rho_{f}}+\frac{\mathrm{wt} \%_{m}}{\rho_{m}}}
$$

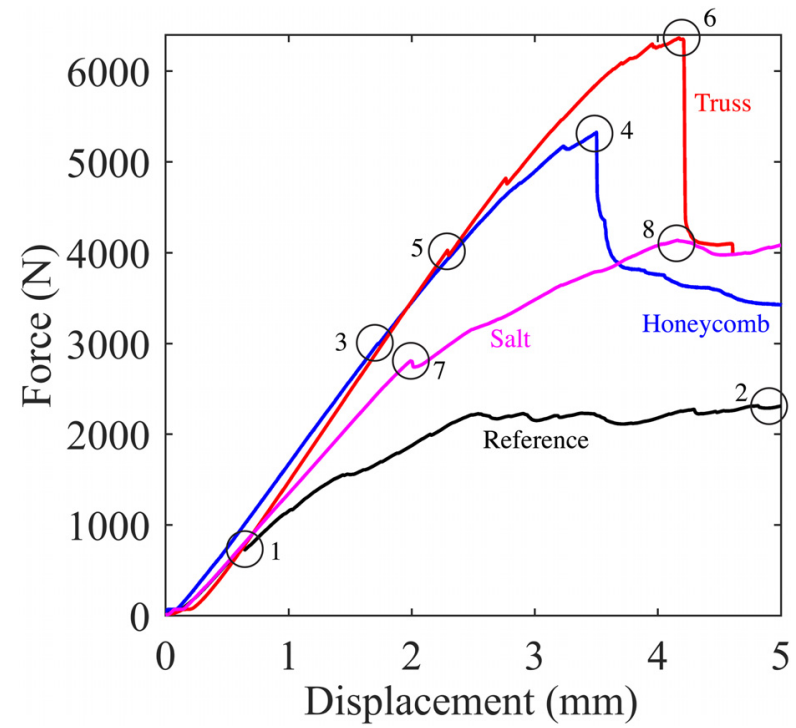

Fig. 16 Force-displacement diagram of representative samples where $\mathrm{wt}_{f_{f, f}}=0.5, \mathrm{wt} \%_{f, \mathrm{UD}}=0.62, \mathrm{wt} \%_{m, f}=0.45, \mathrm{wt} \%_{m, \mathrm{UD}}=$ 0.38 are the weight percentages and $\rho_{f}=1.76 \mathrm{~g} / \mathrm{cm}^{3}, \rho_{m}=$ $1.13 \mathrm{~g} / \mathrm{cm}^{3}$ the densities of the fabric $(f)$, the UD fibers and the matrix, respectively. Based on this information, the fiber volume content $v_{f}$ is calculated to be $44.0 \%$ for the fabric and $51.2 \%$ for the UD.

Figure 19(a) shows a light-microscope image of the longitudinal section of the load introduction area of the tested truss design. The laminate thickness varies between 0.78 and $0.91 \mathrm{~mm}$, which remains within the analytical value of $0.8 \mathrm{~mm}$. The fiber volume content $v_{f}$ ranges between $43.1 \%$ and $50.4 \%$ dependent on the measurement location. The average fiber volume content $v_{f}$ amounts to $46.5 \%$ and is in good agreement with the analytical value for the fabric. The void content was assessed with image analysis and amounts to an average value of $1.32 \%$.

Figure 19(b) shows a close-up of the interface of the CFRP to the core element made of HST DuraForm by SLS. During curing, the excessive resin of the prepreg material takes the contour of the irregularly shaped surface of the 3D-printed core. A layer thickness ranging between 0 and $0.05 \mathrm{~mm}$ is measured. No voids are visible at the interface, leading to the conclusion of a presumably strong interface.

The density of the SLS was assessed using optical microscopy in conjunction with image analysis. Figure 19(c) shows a representative section of the porosity analysis for the DuraForm HST composite material processed using SLS. Depending on the location of the measurement and on the contrast settings, a material density ranging between $84.5 \%$ and $90.3 \%$ is calculated. Due to a lack of comparative values, the porosity is compared to similar materials processed with SLS: Polyamide 12 reaches a density of 94\% [44], while the density of amounts to Nylon 74.7\% [45], and the density of sintered polycarbonate amounts up to $90 \%$ [46]. The values of this study are thus plausible.

(a) Honeycomb design

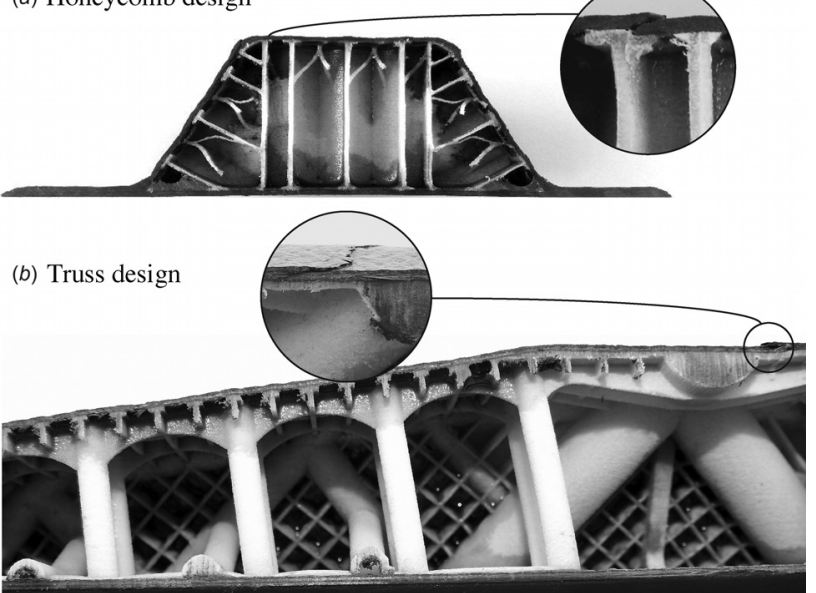

(c) Salt core design

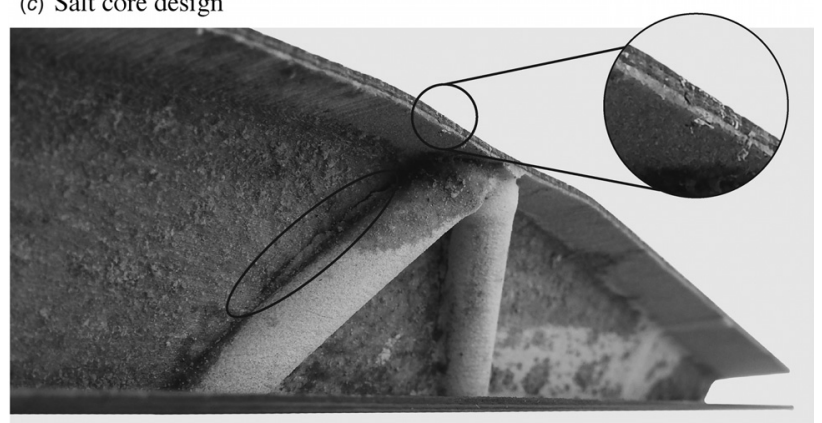

Fig. 17 Section view of tested hat stiffeners. All specimens failed in or next to the load introduction area (encircled). 


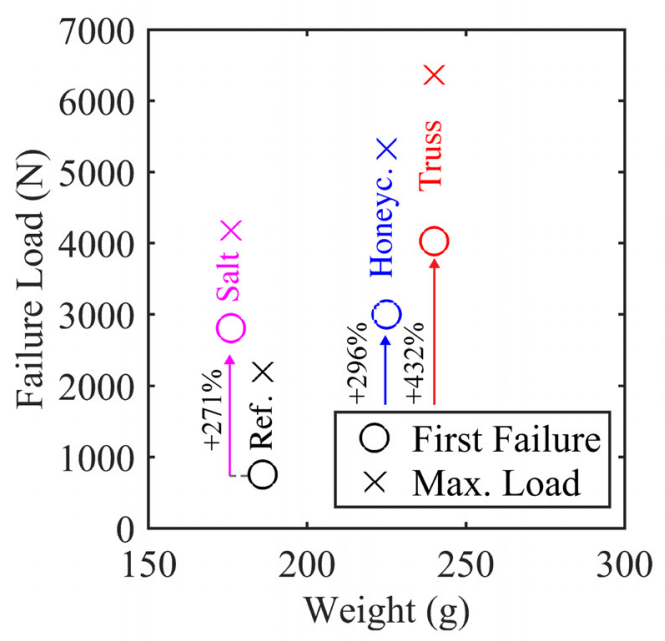

(a)

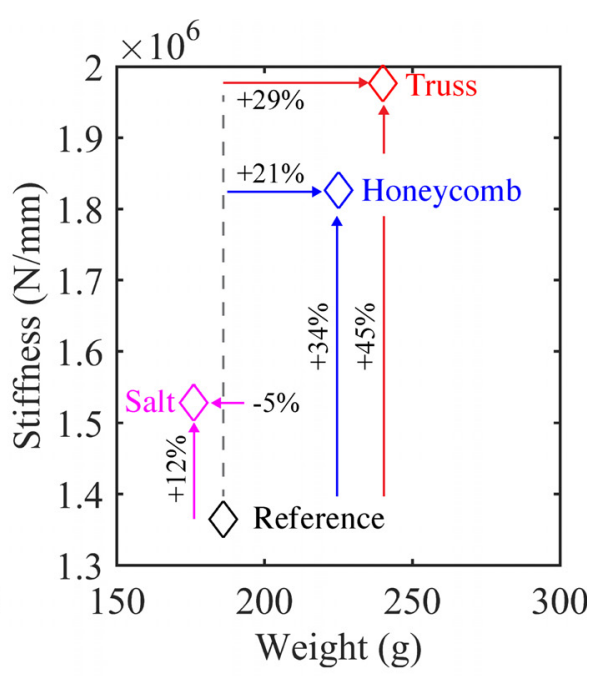

(b)

Fig. 18 Comparison of failure load (a) and bending stiffness (b). Percentage values compared to the reference.

\section{Discussion}

6.1 Comparison of Design Concepts. A novel approach combining additive manufacturing with carbon fiber prepreg for lightweight structures has been proposed. The results show that all AM designs exhibit an improved mechanical performance in terms of first failure load, maximum load, and bending stiffness.

While the honeycomb and the truss design exhibit high absolute breaking loads, their elevated weight reduces the competitiveness of the designs in terms of specific properties. Figure 20 compares the specific mechanical properties of the designs. While the absolute increase in the bending stiffness amounts to $45 \%$ for the truss, and $34 \%$ for the honeycomb concept, the specific bending stiffness only increased by $12 \%$ and $11 \%$, respectively.

This is due to the amount of structural material, which is assigned to the processing loading but remains unloaded in threepoint bending. This effect is highlighted by the simulations. In the case of the truss design, the core weighs $84 \mathrm{~g}$, with $29 \mathrm{~g}$ are assigned to the $3 \mathrm{~PB}$ loading and $55 \mathrm{~g}$ for the processing. A total of $65.5 \%$ of the core weight is therefore required for the processing load case.

Even though AM allows the realization of complex optimized structures with relative densities in the area of 0.14 to 0.15 ( $\rho_{\text {rel }}=\frac{\rho_{\mathrm{HC}}}{\rho_{\mathrm{S}}}=\frac{162}{1200}$ for DuraForm HST composite) for the honeycomb design, a few limitations are observed. Current SLS systems allow the realization of walls with a minimal thickness ranging between 0.4 and $0.7 \mathrm{~mm}$ depending on the machine type, the powder material, and the processing parameters. Structural foams, however, exhibit cell wall thicknesses of approximately $0.1 \mathrm{~mm}$, which are significantly lower and thus allow the creation of structures with lower densities. Increasing the feature resolution of AM systems for the production of lightweight AM honeycomb structures is thus desirable and would allow to exploit additional optimization strategies. For example, the individual cells could be further optimized by sizing the wall thickness of each cell in order to achieve a homogenous stress distribution, as proposed by Riss et al. (44 - CITE). In addition, the increased influence of manufacturing defects on the structural performance should be considered for delicate AM structures including honeycombs [47] or lattices [48].

Another limiting factor is the thermomechanical properties of commercially available material properties for SLS. For example, the tensile yield strength of DuraForm HST Composite decreases by approximately $70 \%$ at $100^{\circ} \mathrm{C}$, compared to the values at room temperature [40]. Recent advancements in the processing of hightemperature materials including PEEK $[49,50]$ will expand the performance envelope for SLS polymers and may be of interest in applications combining AM and CFRP in layup processes.

Design optimization of the structural core may not yield significantly lighter structures for the hat stiffeners presented in this study, as the relevant design load consists of a pressure loading, which is equally distributed on all outer surfaces. Reducing the processing pressure will yield lighter cores; however, fiber volume content and laminate porosity may be affected and should be considered.

Removable cores could represent a change of paradigm: the salt core approach resulted in a competitive design in terms of mechanical performance and weight. The specific stiffness increased by $18 \%$ and the specific first failure load by $290 \%$. Within some limitations, the salt core design can be processed at various pressures and is characterized by a low design effort, especially when compared to the principal stress or the

Table 2 Absolute and specific failure loads, and bending stiffness. Specific properties are divided by the overall structural weight. $\Delta$ : increase/decrease in \%.

\begin{tabular}{|c|c|c|c|c|c|c|c|c|c|c|c|c|}
\hline \multirow[b]{2}{*}{ Design } & \multicolumn{4}{|c|}{ Failure load } & \multicolumn{4}{|c|}{ Spec. fail. load } & \multicolumn{2}{|c|}{ Bending stiffness } & \multicolumn{2}{|c|}{ Spec. bending stiffness } \\
\hline & $\begin{array}{c}\text { First } \\
(\mathrm{N})\end{array}$ & $\begin{array}{c}\Delta \\
(\%)\end{array}$ & $\underset{(\mathrm{N})}{\operatorname{Max} .}$ & $\underset{(\%)}{\Delta}$ & $\begin{array}{c}\text { First } \\
10^{4} \cdot(\mathrm{N} / \mathrm{kg})\end{array}$ & $\begin{array}{c}\Delta \\
(\%)\end{array}$ & $\begin{array}{c}\text { Max. } \\
10^{4} \cdot(\mathrm{N} / \mathrm{kg})\end{array}$ & $\underset{(\%)}{\Delta}$ & $\begin{array}{c}\text { Value } \\
10^{6} \cdot(\mathrm{N} / \mathrm{m})\end{array}$ & $\underset{(\%)}{\Delta}$ & $\begin{array}{l}\text { Value } \\
10^{6} \cdot(\mathrm{N} / \mathrm{m} \cdot \mathrm{kg})\end{array}$ & $\underset{(\%)}{\Delta}$ \\
\hline $51 \mathrm{IG}-\mathrm{F}$ & 757 & 0 & 2200 & 0 & 0.41 & 0 & 1.18 & 0 & 1.36 & 0 & 7.34 & 0 \\
\hline Honeycomb & 3001 & 296 & 5328 & 142 & 1.33 & 224 & 2.37 & 100 & 1.83 & 34 & 8.12 & 11 \\
\hline Truss & 4029 & 432 & 6368 & 190 & 1.68 & 310 & 2.65 & 123 & 1.98 & 45 & 8.24 & 12 \\
\hline Salt & 2808 & 271 & 4180 & 90 & 1.60 & 290 & 2.38 & 101 & 1.53 & 12 & 8.69 & 18 \\
\hline
\end{tabular}


honeycomb designs. The approach is only limited by a few factors: first, access for filling the salt prior to curing and dissolving it afterward is required. Second, the hull made of DuraForm HST adds to the overall weight ( $20 \mathrm{~g}$ or $80 \%$ of the core weight) and showed partial resin inflow during processing. The application of sealing or an increase in the hull thickness may avoid the occurrence of such processing effects. Further research is required in the development of an approach for the additive manufacturing of salt for the production of removable and temperature-resistant structures. Sealing has to be improved. Moreover, the compression properties of salt in combination with the shell should be studied to provide a material data basis for the numerical analysis of salt during processing conditions. In this study, a pressure of 2.5 bar was applied in the autoclave prepreg process, which is characterized by long cycle times. Depending on the compression strength of the salt, the approach might also be suitable for highvolume composite processes including resin transfer molding where pressures of up to 40 bar are applied.

A study to optimize the hull thickness should be conducted. The optimal hull thickness is a trade-off between tightness against resin inflow, structural weight, and robustness. In this study, the functional hull remained in the final AM-CFRP structure; however, rated breaking points could be integrated to mechanically remove parts of the hull for ultra-light applications.

Summarizing, the salt core design combines excellent specific mechanical properties with excellent freedom in design and low processing effort. The geometrical complexity is independent

(a) Truss design

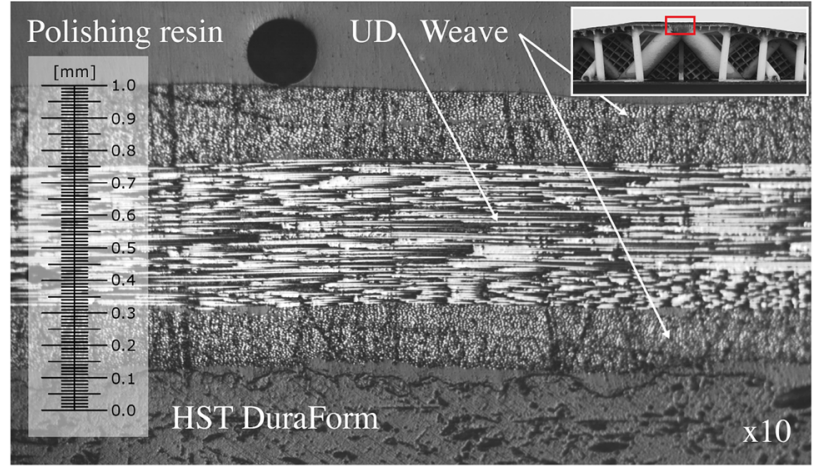

(b) Interface laminate - SLS

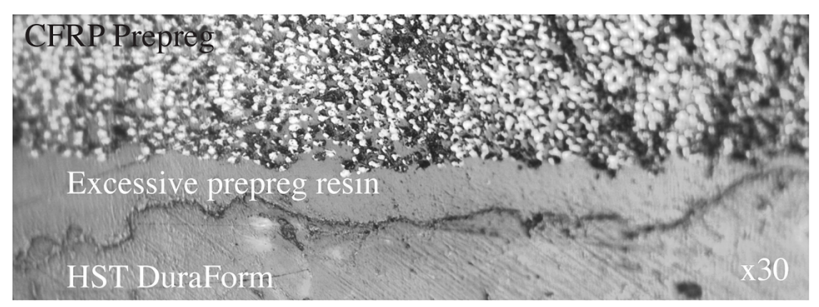

(c) Image processing (porosity of HST DuraForm)

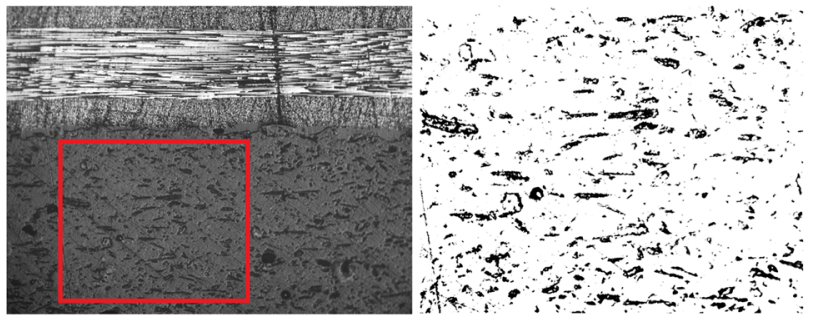

Fig. 19 Light-microscope images showing the section view of the truss design (a), a close view of the interface between the laminate $(b)$ and the HST DuraForm composite material and its porosity (c) from the manufacturing effort, as the complexity is represented with AM. Its applicability thus is manifold with the possibility to integrate additional functionalities into the AM functional hull. It is therefore the favored design approach for the target application.

6.2 Design Space. In this study, a hat-shaped geometry was loaded in three-point bending. For this slender profile, the CFRP sides support the center roller, which is shown by stress peaks in the simulations. The mechanical effect of locally embedded elements made by AM is expected to be more pronounced in large surface structures (e.g., panels); however, this largely depends on the load case and the geometry.

A lengthwise chamfer of the profile results in a significant weight reduction for $\mathrm{AM}$ cores (e.g., $\approx 47 \mathrm{~g}$ for the honeycomb concept). However, chamfering the reference core would entail a weight difference of only $7 \mathrm{~g}$, which is insignificant in comparison to the overall weight of the structure. This is due to the great difference between the densities of the IG-51 foam and the polymeric parts made by SLS.

It should be noted that the hat-stiffener beam is a chosen geometry to compare design approaches and does not represent the ultimate application. Target applications consist of complex-shaped structures such as winglets or doubly curved sandwiches with integrated functionalities. The design freedom of AM most probably will have a greater impact on such applications which are more difficult to produce using conventional techniques.

6.3 The Value of Additive Manufacturing for Composites. The combination of additive manufacturing with carbon fiberreinforced polymers in autoclave layup processes is a suitable approach for the manufacturing of customized, lightweight, and geometrically complex structures. Based on the freedom of design and the possibility to integrate additional functionalities, AM is found to be more advantageous than conventional techniques for the following three applications: first, AM allows complex-shaped tooling to be produced for the layup of CFRP without any significant manufacturing effort. Second, the mechanical properties can be tailored to local loads by placing material where necessary, which allows for optimal lightweight designs. Third, AM can improve the production of composite parts by integrating layup references, positioning, and structural curing aids.

We therefore consider this technology to be promising for structural applications that have to be lightweight, are complexshaped, and have integrated functionalities. Areas of applications are found in robotics, prostheses and exoskeletons, aerospace research, and flying vehicles.

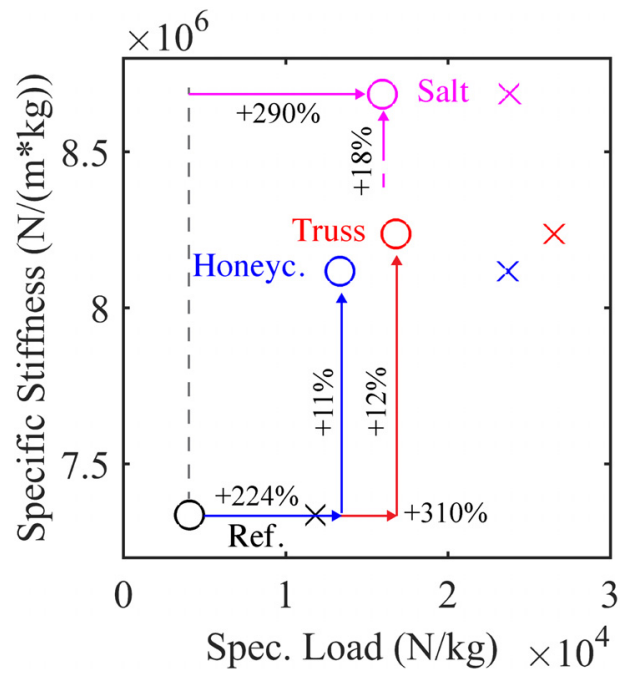

Fig. 20 Comparison of specific stiffness and specific failure load. Percentages compare to reference design. 


\section{Conclusions}

The combination of additive manufacturing with carbon fiber prepregs produced in an autoclave layup process can yield competitive lightweight structures when employed in combination with a temperature- and compressive-resistant filler material.

With an increase in the specific first failure load by $290 \%$ and an overall weight reduction by $5 \%$, the performance of the salt core design is promising. The designs consisting exclusively of polymeric cores made by SLS exhibit a specific first failure load increased by up to $310 \%$, and an increase in the specific bending stiffness by up to $12 \%$. However, the mechanical advantages are counteracted by a weight penalty ranging between $21 \%$ and $29 \%$. The results indicate that polymeric materials processed by SLS do not fully satisfy the thermomechanical requirements for inautoclave applications. Future work should therefore be dedicated to temperature-resistant materials that are processed by $\mathrm{AM}$ to fabricate complex-shaped cores.

\section{Acknowledgment}

We thank Professor P. Ermanni of ETH Zurich for providing unlimited access to the laboratory facilities of CMASLab, Professor G. Terrasi and T. Lämmlein of EMPA for assisting in three-point bending testing. We also thank R. Kussmaul of ETH Zurich for providing the optimization algorithms on which the truss design is based and L. Völker for his support on the honeycomb design. Financial support from the Product Development Group Zurich pdlz of ETH Zurich is gratefully acknowledged.

\section{Appendix: Material Properties}

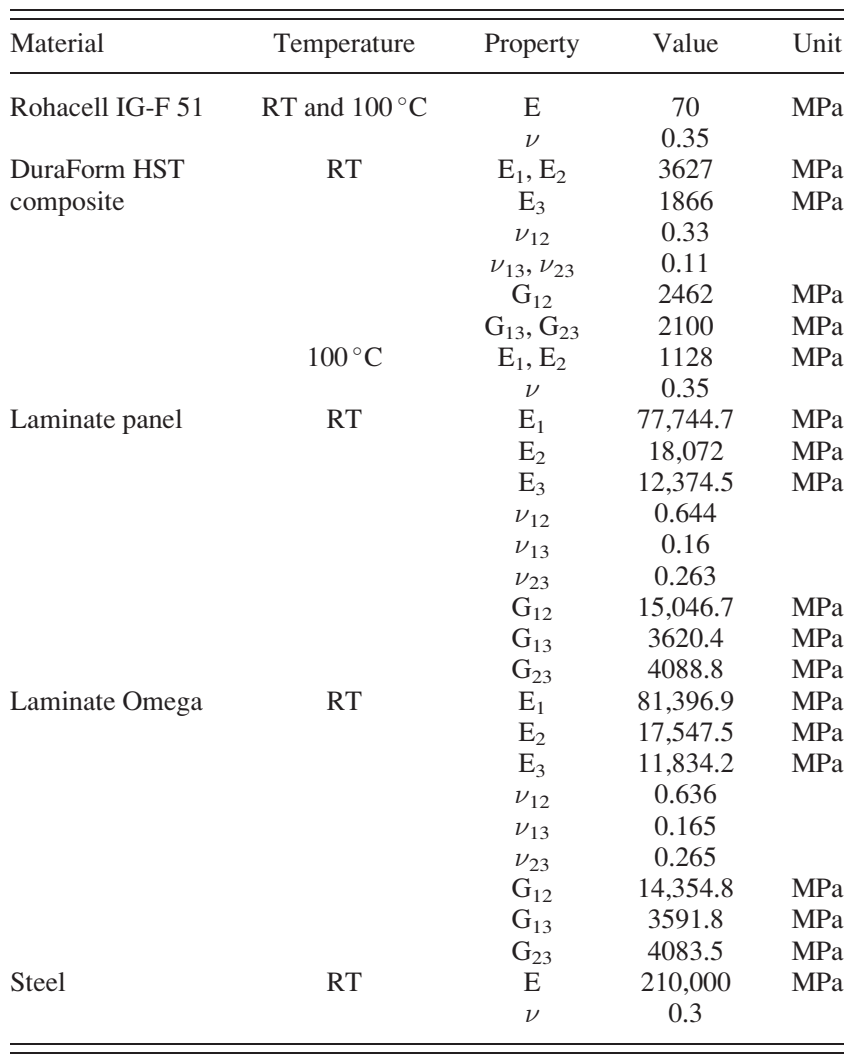

\section{References}

[1] Evans, A. G., 2001, "Lightweight Materials and Structures," MRS Bull., 26(10), pp. 790-797.

[2] Davies, J. M., 2001, Lightweight Sandwich Construction, Wiley-Blackwell, Oxford, UK.
[3] Herrmann, A. S., Zahlen, P. C., Zuardy, I., 2005, "Sandwich Structures Technology in Commercial Aviation," Sandwich Structures 7: Advancing with Sandwich Structures and Materials, Thomsen, O., Bozhevolnaya, E., and Lyckegaard, A. eds., Springer, Dordrecht, The Netherlands.

[4] Anders, M., Zebrine, D., Centea, T., and Nutt, S., 2017, "In Situ Observations and Pressure Measurements for Autoclave Co-Cure of Honeycomb Core Sandwich Structures,” ASME J. Manuf. Sci. Eng., 139(11), p. 111012.

[5] Kodiyalam, S., Nagendra, S., and DeStefano, J., 1996, "Composite Sandwich Structure Optimization With Application to Satellite Components," AIAA J. 34(3), pp. 614-621.

[6] Huang, X., and Xie, Y. M., 2008, "Optimal Design of Periodic Structures Using Evolutionary Topology Optimization,” Struct. Multidiscip. Optim., 36(6), pp. 597-606.

[7] Gibson, L. J., and Ashby, M. F., 1999, Cellular Solids: Structure and Properties, Cambridge University Press, Cambridge, UK.

[8] Huang, S. N., and Alspaugh, D. W., 1974, "Minimum Weight Sandwich Beam Design," AIAA J., 12(12), pp. 1617-1618.

[9] Li, X., Li, G., Wang, C. H., and You, M., 2012, "Optimisation of Composite Sandwich Structures Subjected to Combined Torsion and Bending Stiffness Requirements," Appl. Compos. Mater., 19(3-4), pp. 689-704.

[10] Catapano, A., and Montemurro, M., 2014, "A Multi-Scale Approach for the Optimum Design of Sandwich Plates With Honeycomb CorePart I: Homogenization of Core Properties," Compos. Struct., 118, pp. 664-676.

[11] Catapano, A., and Montemurro, M., 2014, "A Multi-Scale Approach for the Optimum Design of Sandwich Plates With Honeycomb Core-Part II: The Optimization Strategy," Comp. Struct., 118, pp. 677-690.

[12] Krieglsteiner, J., Horst, P., and Schmidt, C., 2014, "Characterization of FiberReinforced Stiffener Profiles for Aircraft Fuselage Preliminary Structural Design," 16th European Conference on Composite Materials (ECCM), Seville, Spain, June 22-26, pp. 1-8.

[13] Tosh, M. W., and Kelly, D. W., 2001, "Fibre Steering for a Composite CBeam," Comp. Struct., 53(2), pp. 133-141.

[14] Alinia, M. M., and Moosavi, S. H., 2008, "A Parametric Study on the Longitudinal Stiffeners of Web Panels," Thin-Walled Struct., 46(11), pp. 1212-1223

[15] Kaufmann, M., Zenkert, D., and Mattei, C., 2008, "Cost Optimization of Composite Aircraft Structures Including Variable Laminate Qualities," Comp. Sci. Technol., 68(13), pp. 2748-2754.

[16] Mukhopadhyay, M., 2004, Mechanics of Composite Materials and Structures, University Press, Hyderguda, India.

[17] Zenkert, D., 1995, An Introduction to Sandwich Construction, Engineering Materials Advisory Services, London.

[18] Gutowski, T. G., 1997, Advanced Composites Manufacturing, Wiley, Cambridge, UK.

[19] Advanced Ceramics Manufacturing, 2017, "Advanced Ceramics Manufacturing," Tucson, AZ, accessed June 20, 2017, http://www.acmtucson.com

[20] Black, S., 2015, "3D Printing Moves Into Tooling Components," CompositesWorld, Cincinnati, OH, accessed June 15, 2017, https://www.compositesworld. com/articles/3d-printing-moves-into-tooling-components

[21] ASTM, 2012, "Standard Terminology for Additive Manufacturing Technologies," West Conshohocken, PA, Standard No. ASTM F2792-12a.

[22] Stratasys, 2017, "Introduction to Additive Manufacturing for Composites," Stratasys, Eden Prairie, MN, accessed June 20, 2017, http://www.stratasys.com/ de/campaign/ebook/additive-manufacturing-for-composites

[23] Li, H., Taylor, G., Bheemreddy, V., Iyibilgin, O., Leu, M., and Chandrashekhara, K., 2015, "Modeling and Characterization of Fused Deposition Modeling Tooling for Vacuum Assisted Resin Transfer Molding Process," Addit. Manuf., 7, pp. 64-72.

[24] Lušic, M., Schneider, K., and Hornfeck, R., 2016, "A Case Study on the Capability of Rapid Tooling Thermoplastic Laminating Moulds for Manufacturing of CFRP Components in Autoclaves," Procedia CIRP, 50, pp. 390-395.

[25] Prüß, H., and Vietor, T., 2015, "Design for Fiber-Reinforced Additive Manufacturing," ASME J. Mech. Des., 137(11), p. 111409.

[26] Hassen, A., Lindahl, J., Chen, J., Post, B., Love, L., and Kunc, V., 2016 "Additive Manufacturing of Composite Tooling Using High Temperature Thermoplastic Materials," SAMPE Conference Proceedings, Long Beach, CA, May 23-26, pp. 2648-2658.

[27] Stratasys, 2017, "Sacrificial Tooling and Mandrels Composite Part FabricationDesign Guide," Stratasys, Eden Prairie, MN, accessed June 21, 2017, http:// www.stratasys.com/solutions/additive-manufacturing/tooling/composite-tooling

[28] Türk, D.-A., Triebe, L., and Meboldt, M., 2016, "Combining Additive Manufacturing With Advanced Composites for Highly Integrated Robotic Structures," Procedia CIRP, 50, pp. 402-407.

[29] Nygaard, J. V., and Lyckegaard, A., 2007, "Sandwich Beam With a Periodical and Graded Core Manufactured Using Rapid Prototyping," J. Sandwich Struct. Mater., 9(4), pp. 365-376.

[30] Williams, R. R., Howard, W. E., and Martin, S. M., 2011, "Composite Sandwich Structures With Rapid Prototyped Cores,” Rapid Prototyping J., 17(2), pp. 92-97.

[31] Li, T., and Wang, L., 2017, "Bending Behavior of Sandwich Composite Structures With Tunable 3D-Printed Core Materials," Compos. Struct., 175, pp. 46-57.

[32] Morena, J. J., 2011, Mold Fabrications, Wiley Encyclopedia of Composites, Hoboken, NJ.

[33] Bitzer, T., 2012, Honeycomb Technology: Materials, Design, Manufacturing, Applications and Testing, Springer Science \& Business Media, Dordrecht, The Netherlands. 
[34] Stankunas, T., Mazenko, D., and Jensen, G., 1989, "Cocure Investigation of a Honeycomb Reinforced Spacecraft Structure," 21st International SAMPE Technical Conference, Atlantic City, NJ, pp. 176-188.

[35] Campbell, F. C., Jr., 2003, Manufacturing Processes for Advanced Composites, Elsevier, Oxford, UK.

[36] ROHACELL, 2017, "Rohacell IG-F Datasheet," Essen, Germany, accessed May 8, 2017, http://www.rohacell.com/sites/lists/RE/DocumentsHP/ROHACELL\%20IG_ IG-F\%20Product\%20Information.pdf

[37] Sigmund, O., Aage, N., and Andreassen, E., 2016, "On the (Non-)Optimality of Michell Structures," Struct. Multidiscip. Optim., 54(2), pp. 361-373.

[38] Kussmaul, R., Zogg, M., and Ermanni, P., 2018, “An Optimality Criteria-Based Algorithm for Efficient Design Optimization of Laminated Composites Using Concurrent Resizing and Scaling," Struct. Multidiscip. Optim. (epub).

[39] Sriapai, T., Walsri, C., and Fuenkajorn, K., 2012, "Effect of Temperature on Compressive and Tensile Strength of Salt," ScienceAsia, 38(2), pp. 166-174.

[40] 3D Systems, 2017, "DuraForm HST Composite Datasheet," 3D Systems, Rock Hill, SC, accessed May 8, 2017, https://www.3dsystems.com/materials/duraformhst-composite/tech-specs

[41] Schmid, M., 2015, Selektives Lasersintern (SLS) Mit Kunststoffen, Hanser, Munich, Germany.

[42] Türk, D. A., Brenni, F., Zogg, M., and Meboldt, M., 2017, "Mechanical Characterization of 3D Printed Polymers for Fiber Reinforced Polymers Processing," Mater. Des., 118, pp. 256-265.
[43] Gere, J. M., and Goodno, B. J., 2013, Mechanics of Materials, Cengage Learning, Stamford, CT.

[44] Dewulf, W., Pavan, M., Craeghs, T., and Kruth, J.-P., 2016, "Using X-Ray Computed Tomography to Improve the Porosity Level of Polyamide-12 Laser Sintered Parts," CIRP Ann., 65(1), pp. 205-208.

[45] Shaw, B., and Dirven, S., 2016, "Investigation of Porosity and Mechanical Properties of Nylon SLS Structures," 23rd International Conference on Mechatronics and Machine Vision in Practice (M2VIP), Nanjing, China, Nov. 28-30, pp. 1-6.

[46] Ho, H. C. H., Gibson, I., and Cheung, W. L., 1999, "Effects of Energy Density on Morphology and Properties of Selective Laser Sintered Polycarbonate," J. Mater. Process. Technol., 89-90, pp. 204-210.

[47] Rahman, K. M., Hu, Z., and Letcher, T., 2017, "In-Plane Stiffness of Additively Manufactured Hierarchical Honeycomb Metamaterials With Defects," ASME J. Manuf. Sci. Eng., 140(1), p. 011007.

[48] Beyer, D., and Figueroa, D., 2016, "Design and Analysis of Lattice for Additive Manufacturing,” ASME J. Manuf. Sci. Eng., 138(12), p. 121015.

[49] Schmidt, M., Pohle, D., and Rechtenwald, T., 2007, "Selective Laser Sintering of PEEK," CIRP Ann. Manuf. Technol., 56(1), pp. 205-208.

[50] Fish, S., Booth, J. C., Kubiak, S. T., Wroe, W. W., Bryant, A. D., Moser, D. R., and Beaman, J. J., 2015, "Design and Subsystem Development of a High Temperature Selective Laser Sintering Machine for Enhanced Process Monitoring and Control," Addit. Manuf., 5, pp. 60-67. 